\title{
Moon phase and nocturnal density of Atlantic salmon parr in the Sainte-Marguerite River, Québec
}

\author{
I. IMRE* AND D. BOISCLAIR \\ Département de Sciences Biologiques, Université de Montréal, C.P. 6128, Succursale \\ Centre-Ville, Montréal, Québec H3C 3J7, Canada
}

(Received 6 April 2004, Accepted 29 September 2004)

\begin{abstract}
Nocturnal underwater counts of Atlantic salmon Salmo salar parr were made on four consecutive occasions (two lunar cycles, samplings at both the full and new moon) at four $40 \mathrm{~m}$ long sites in the Sainte-Marguerite River, Québec, Canada, between 30 June and 14 August 2003. Atlantic salmon parr counts did not differ significantly between moon phases. Cloud cover ranged from 0 to $100 \%$ during the study, and had no significant effect on parr counts. There were significantly more Atlantic salmon parr in the near shore than in the midstream areas. The findings of this study suggest that the sampling strategy of summer studies aimed at assessing population abundance or developing habitat quality models can be designed without taking moon phase or cloud cover into consideration, but it should account for the higher relative abundance of Atlantic salmon parr in the near shore areas as compared to areas closer to the middle of streams.

(C) 2005 The Fisheries Society of the British Isles
\end{abstract}

Key words: moon phase; nocturnal density; population assessment; Salmo salar.

\section{INTRODUCTION}

The freshwater phase is an important period of the Atlantic salmon Salmo salar L. life cycle, because reproduction, early growth and survivorship during this phase determine the abundance of juveniles (Poff \& Huryn, 1998). The lack of conservation and proper management of the key freshwater habitats is thought to be one of the major factors that has contributed to the decline of Atlantic salmon populations (Armstrong et al., 1998).

Numerical habitat models (NHM, Guay et al., 2000) can be important for the development of large-scale conservation and management policies in fresh water. As habitat quality is often evaluated on the basis of the abundance of fishes found within a given area, it is vitally important to identify and predict spatial and temporal changes in habitat. For example, locations preferred and avoided by Atlantic salmon parr have been generally determined during daytime (Girard, 2002; Guay et al., 2003), because stream-dwelling juvenile salmonids were traditionally considered to be feeding actively during dawn, full daylight and dusk in the summer (Kalleberg, 1958; Elliott, 1970, 1973;

\footnotetext{
*Author to whom correspondence should be addressed. Tel.: +15143436111 ext. 13187; fax: +1 514343 2293; email: istvan.imre@umontreal.ca
} 
Wańkowski \& Thorpe, 1979; Bachman, 1984). Recent studies, however, suggest that in the summer, even at high water temperatures, there are more visible Atlantic salmon parr on or above the substratum at night than during the day (Gries et al., 1997; Breau, 2003; Imre \& Boisclair, 2004). Information on habitat quality obtained from daytime observations of habitat selection by Atlantic salmon parr may provide only a partial perspective of habitat requirements for these fish. A habitat considered relatively poor during the day may become better if observations are carried out at night. Hence, proper evaluation of habitat requirements for Atlantic salmon parr may necessitate data collection during both the day and night.

In addition to diel changes in the abundance of visible juvenile Atlantic salmon, there is evidence to suggest that other factors could also be important for the accurate determination of Atlantic salmon abundance and distribution. Contor \& Griffith (1995) noted that the nocturnal density of visible juvenile rainbow trout Oncorhynchus mykiss (Walbaum) in a river substantially decreased in the presence of moonlight or artificial light. Similarly, several studies examining vertical or horizontal migration of fishes noted that there were substantially less fishes observed in the pelagic zone of lakes during nights with a full moon than nights with a new moon (Luecke \& Wurtsbaugh, 1993; Comeau \& Boisclair, 1998; Gaudreau \& Boisclair, 2000). This finding was thought to be due to predator avoidance during a full moon (Luecke \& Wurtsbaugh, 1993; Contor \& Griffith, 1995; Gaudreau \& Boisclair, 2000), and they suggest that moon phase could significantly influence estimates of fish abundance.

There is an alternative hypothesis that predicts a higher visible Atlantic salmon parr density during nights with a full moon compared to nights with a new moon. The number of drifting benthic invertebrates is substantially higher at night than during the day (Waters, 1962; Elliott, 1970, 1973). Perhaps as a response to this higher food availability, Atlantic salmon parr were found to be foraging at night, both in experimental studies (Valdimarsson \& Metcalfe, 1999) and in rivers (Amundsen et al., 1999, 2000). The feeding efficiency of Atlantic salmon parr, however, decreases with decreasing light intensity, their nocturnal feeding efficiency at typical night-time light intensities being only about one tenth of their daytime efficiency (Fraser \& Metcalfe, 1997). Since higher ambient light levels would substantially improve their ability to detect drift, Atlantic salmon parr should be more active during a full moon, as compared to a new moon.

The objective of this study was to test the above hypotheses by comparing the number of visible Atlantic salmon parr during nights with new moon to those with a full moon.

\section{MATERIALS AND METHODS}

\section{STUDY AREA AND SAMPLING SITES}

Sampling was conducted in the main branch of the Sainte-Marguerite River, a tributary of the Saguenay River, Québec, Canada $\left(48^{\circ} 23^{\prime} \mathrm{N} ; 70^{\circ} 12^{\prime} \mathrm{W}\right.$; Fig. 1$)$. The Atlantic salmon coexists with several other fish species in the Sainte-Marguerite River including 


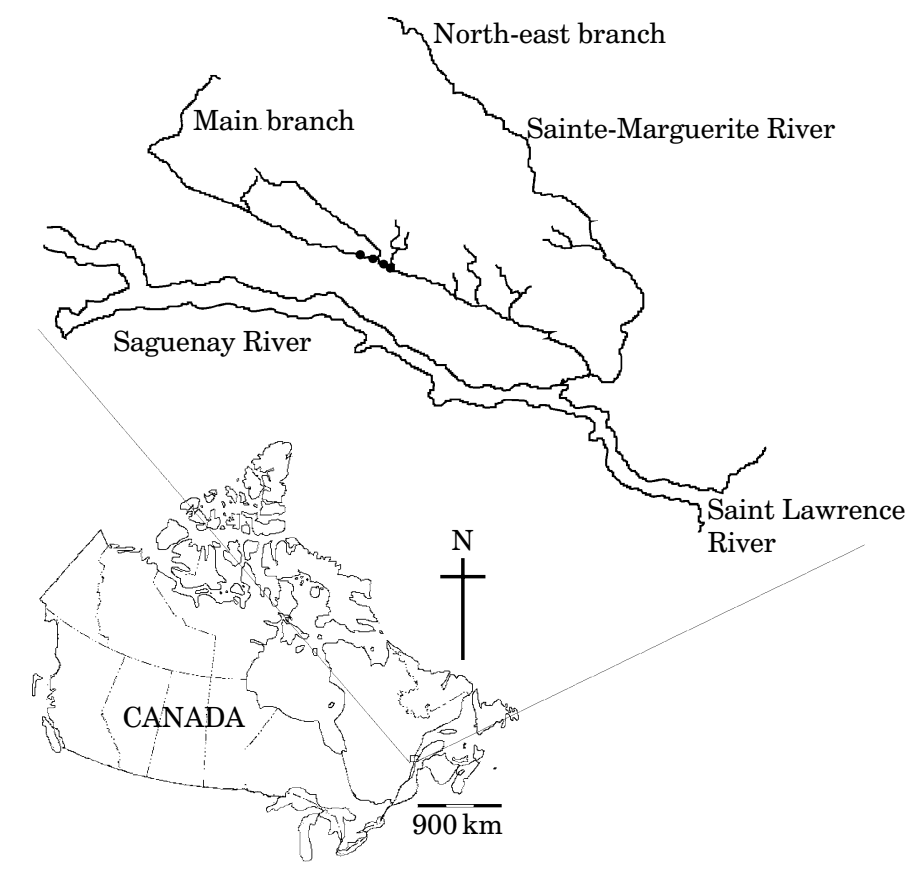

FIG. 1. Location of the Sainte-Marguerite River (modified from Guay et al., 2000). The location of the four sampling sites $(\bullet)$ are indicated.

brook charr Salvelinus fontinalis (Mitchill), American eel Anguilla rostrata (Lesueur), longnose dace Rhinichthys cataractae (Valenciennes), longnose sucker Catostomus catostomus (Forster) and sea lamprey Petromyzon marinus L.

Four $40 \mathrm{~m}$ long sites were selected in the Sainte-Marguerite River and their physical characteristics and substratum composition were surveyed on 1 July 2003 (Table I). Substratum type was classified as clay, silt, sand, gravel, pebble, cobble or boulder based on particle size as described by Gordon et al. (1992), with the exception that coarse and very coarse gravel were classified as pebble. The second, third and fourth sites were located 880, 2140 and $5190 \mathrm{~m}$ upstream, respectively, from the first site.

\section{DATA COLLECTION}

To quantify the abundance of Atlantic salmon parr at full and new moons, underwater surveys (visual sampling at four sites at night) were conducted on 30 June, 13 July, 1 August and 14 August 2003 (two complete moon cycles). Sampling dates were chosen such that the fraction of the moon illuminated at midnight was not $>10 \%$, and not $<90 \%$ at new moon and full moon, respectively.

Four snorkellers sampled four separate counting strips $(c .3 \mathrm{~m}$ wide $\times 40 \mathrm{~m}$ long) at each site, except the second site, where only three strips were sampled due to very high water velocity $\left(>1 \mathrm{~m} \mathrm{~s}^{-1}\right)$ in some portions of the site. The counting strips were located in both near-shore and midstream areas. The snorkellers entered the river downstream from the site and counted all the visible Atlantic salmon parr while slowly moving upstream. As age $1+$ and $2+$ year juvenile Atlantic salmon could not be discriminated absolutely using only visual observations, they were both included in the sampling strip counts. A waterproof hand-held white light was used for sampling, with the light beam directed at the surface of the water (Gries et al., 1997), in order to minimize the potential disturbance to the fish. The fish did not appear to be disturbed by the light; no fish were observed to leave from, or to be attracted to, the observation area during surveys. 
Table I. Physical characteristics and substratum composition of the four survey sites in the Sainte-Marguerite River

\begin{tabular}{|c|c|c|c|c|c|c|c|c|c|c|c|}
\hline \multirow[b]{2}{*}{ Site } & \multirow{2}{*}{$\begin{array}{l}\text { Habitat } \\
\text { type }\end{array}$} & \multicolumn{7}{|c|}{$\begin{array}{l}\text { Substratum composition } \\
\qquad(\%)\end{array}$} & \multirow{2}{*}{$\begin{array}{c}\text { Mean } \pm \text { S.D. } \\
\text { water } \\
\text { depth } \\
\text { (m) }\end{array}$} & \multirow{2}{*}{$\begin{array}{l}\text { Mean } \pm \text { S.D. } \\
\text { wetted } \\
\text { width } \\
\text { (m) }\end{array}$} & \multirow{2}{*}{$\begin{array}{c}\text { Mean } \pm \text { S.D. } \\
\text { water } \\
\text { velocity } \\
\left(\mathrm{m} \mathrm{s}^{-1}\right)\end{array}$} \\
\hline & & $\mathrm{Cl}$ & $\mathrm{Si}$ & $\mathrm{Sa}$ & $\mathrm{Gr}$ & $\mathrm{Pe}$ & $\mathrm{Co}$ & Bo & & & \\
\hline First & Riffle-run & 0 & 0 & $3 \cdot 5$ & $3 \cdot 5$ & 8 & 61 & 24 & $0 \cdot 4 \pm 0 \cdot 2$ & $25 \pm 5$ & $0 \cdot 5 \pm 0 \cdot 3$ \\
\hline Second & Riffle-run & 0 & 0 & $0 \cdot 5$ & $0 \cdot 8$ & $16 \cdot 5$ & $65 \cdot 7$ & $16 \cdot 5$ & $0 \cdot 3 \pm 0 \cdot 2$ & $38 \pm 5$ & $0 \cdot 6 \pm 0 \cdot 2$ \\
\hline Third & Run & 0 & 0 & 0 & 17 & 17 & 43 & 23 & $0 \cdot 5 \pm 0 \cdot 4$ & $42 \pm 2$ & $0 \cdot 4 \pm 0 \cdot 2$ \\
\hline Fourth & Riffle-run & 0 & 0 & $2 \cdot 7$ & $21 \cdot 6$ & $5 \cdot 5$ & $48 \cdot 6$ & $21 \cdot 6$ & $0 \cdot 5 \pm 0 \cdot 2$ & $39 \pm 3$ & $0 \cdot 5 \pm 0 \cdot 3$ \\
\hline
\end{tabular}

$\mathrm{Cl}$, clay; Si, silt; $\mathrm{Sa}$, sand; $\mathrm{Gr}$, gravel; $\mathrm{Pe}$, pebble; Co, cobble; Bo, boulder.

The sampling was performed between 2140 and 0146 hours at night, under very good to excellent underwater visibility conditions $(c .8-10 \mathrm{~m})$. Each survey was completed within $3 \mathrm{~h}$. The discharge of the river, measured at a station located $c .15 \mathrm{~km}$ upstream of the first site, was obtained for the beginning and the end of each survey. Water temperature and cloud cover were recorded at the beginning, middle and end of sampling at each site (Table II).

\section{STATISTICAL ANALYSES}

The number of parr visible in each counting strip at night was analysed with a mixed model repeated measures ANOVA. Site and counting strip position were considered independent variables, while moon phase (full or new moon) and moon cycle (first and second new and full moon cycle) were treated as repeated measures factors. All data were ln transformed to meet the assumptions of repeated measures ANOVA. Nontransformed data, however, were used for the descriptive statistics reported in the figures.

The potential effect of night-time river discharge, cloud cover and water temperature on parr non-transformed mean site counts over the sampling period was investigated with regression analyses. All statistical tests were performed using Statistica 5.0 (StatSoft, 1995). The level of significance was 0.05 for all tests.

TABLE II. Environmental variables measured at the four survey sites during the four sampling occasions in the Sainte-Marguerite River. The cloud cover and water temperature values are the means of data collected at the beginning, middle and end of sampling at each site

\begin{tabular}{llccccc}
\hline & & & \multicolumn{3}{c}{ Sampling date } \\
\cline { 4 - 6 } Variables & Site & 30 June & 13 July & 1 August & 14 August \\
\hline Cloud cover $(\%)$ & First & 0 & 65 & 0 & 0 \\
& Second & 2 & 94 & 0 & 0 \\
& Third & 5 & 100 & 62 & 2 \\
\multirow{2}{*}{ Water temperature $\left({ }^{\circ} \mathrm{C}\right)$} & Fourth & 22 & 100 & 62 & 0 \\
& First & 15 & 16 & 16 & 16 \\
& Second & 14 & 15 & 16 & 17 \\
\multirow{2}{*}{ Discharge $\left(\mathrm{m}^{3} \mathrm{~s}^{-1}\right)$} & Third & 14 & 15 & 17 & 17 \\
& Fourth & 13 & 15 & 17 & $17 \cdot 5$ \\
& & $3 \cdot 8$ & $3 \cdot 0$ & $5 \cdot 6$ & $5 \cdot 7$ \\
\hline
\end{tabular}




\section{RESULTS}

Overall, 378 Atlantic salmon parr were counted at night. On average, there were mean \pm s.E. $6 \cdot 3 \pm 0.7$ parr observed at individual counting strips $(\mathrm{CV}=0 \cdot 88, n=60)$. The moon phase did not seem to influence the number of visible parr $\left(F_{1,7}, P=0.507\right.$, Fig. 2$)$. The number of visible fish did not differ significantly between the first (30 June to 13 July 2003) and second (1 August to 14 August 2003) complete moon cycle over the observation period $\left(F_{1,7}\right.$, $P=0.967$, Fig. 3).

The number of visible Atlantic salmon parr differed significantly between sites $\left(F_{3,7}, P=0.049\right)$ and between near-shore and midstream areas $\left(F_{1,7}\right.$, $P=0.002$, Fig. 4$)$. On average, there were $c .2 \cdot 5$ times as many fish counted in individual counting strips located near the shore (mean \pm S.E. $8 \cdot 7 \pm 1 \cdot 1)$ than closer to the middle of the stream (mean \pm S.E. $3 \cdot 5 \pm 0 \cdot 4$ ).

The discharge of the river varied between sampling occasions (Table II), but it did not seem to influence the mean number of parr counted at each site $(r=-0 \cdot 18, P=0 \cdot 496, n=16)$. Over the entire sampling period, the cloud cover and the temperature of the water recorded at the time of sampling varied between $0-100 \%$ and $13 \cdot 0-18 \cdot 0^{\circ} \mathrm{C}$, respectively. Despite the high cloud cover during specific surveys, no rain occurred during the nights of the surveys. The mean site counts of Atlantic salmon parr were not related to the mean cloud cover $(r=0.06, P=0.815, n=16)$ or mean water temperature $(r=0.04$, $P=0 \cdot 876, n=16)$ measured at each site at the time of sampling.

\section{DISCUSSION}

The results of this study do not support either the predator avoidance or the food hypothesis, and they suggest that moon phase does not influence the nocturnal density of Atlantic salmon parr. This finding is surprising, because Contor \& Griffith (1995) found that, presumably as a predator avoidance

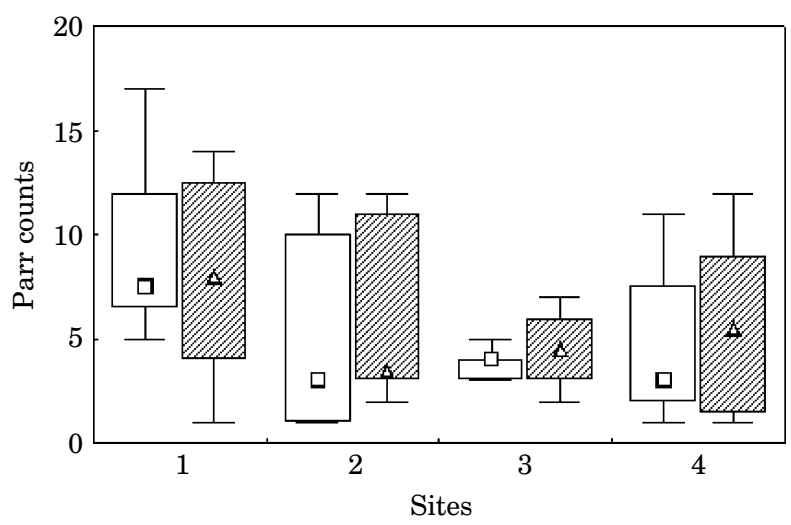

FIG. 2. Median (box: 25\%, 75\%; whisker: non-outlier minimum, non-outlier maximum) counts of Atlantic salmon parr sampled at four sites during full moon ( $\square$ ) and new moon (ग/W ) in the SainteMarguerite River. The descriptive statistics are based on all counting strips at each site over two sampling occasions for both the full and new moon $(n=8$, with the exception of site 2 where $n=6)$. 


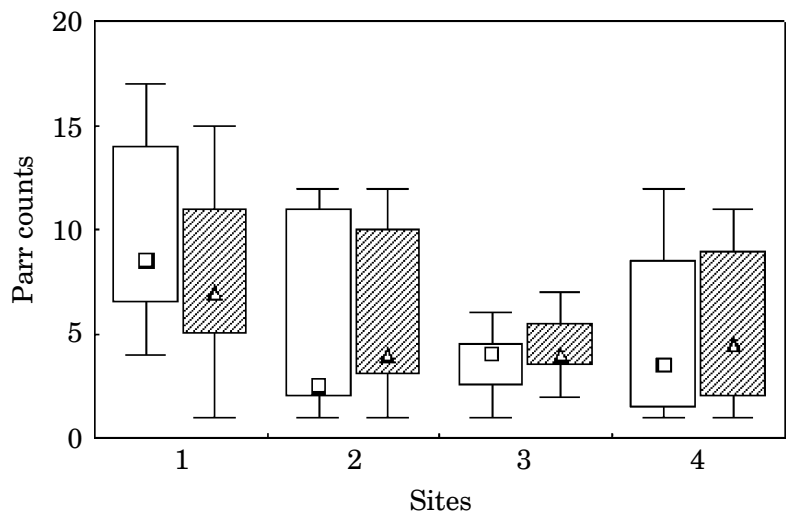

FIG. 3. Median (box: $25 \%, 75 \%$; whisker: non-outlier minimum, non-outlier maximum) counts of Atlantic salmon parr sampled at four sites during the first moon cycle $(\square)$ and second moon cycle (U/A ) in the Sainte-Marguerite River. The descriptive statistics are based on all counting strips at each site over two sampling occasions for both the first and second moon cycle $(n=8$, with the exception of site 2 where $n=6$ ).

adaptation, the number of visible juvenile rainbow trout decreased by $c .73$ and $28 \%$ in the presence of moonlight and artificial light, respectively, in an Idaho river. In addition, the predominantly nocturnal activity of Atlantic salmon parr noted in the summer (Gries et al., 1997; Breau, 2003; Imre \& Boisclair, 2004), late autumn and winter (Fraser et al., 1993; Bremset, 2000) has also been implied to be due to predator avoidance (Fraser et al., 1993, 1995; Gries et al., 1997; Breau, 2003).

Substantial evidence from lake studies indicates that moonlight can affect the number of fishes found in the surface waters of lakes (Luecke \& Wurtsbaugh, 1993; Comeau \& Boisclair, 1998; Gaudreau \& Boisclair, 2000). For example,

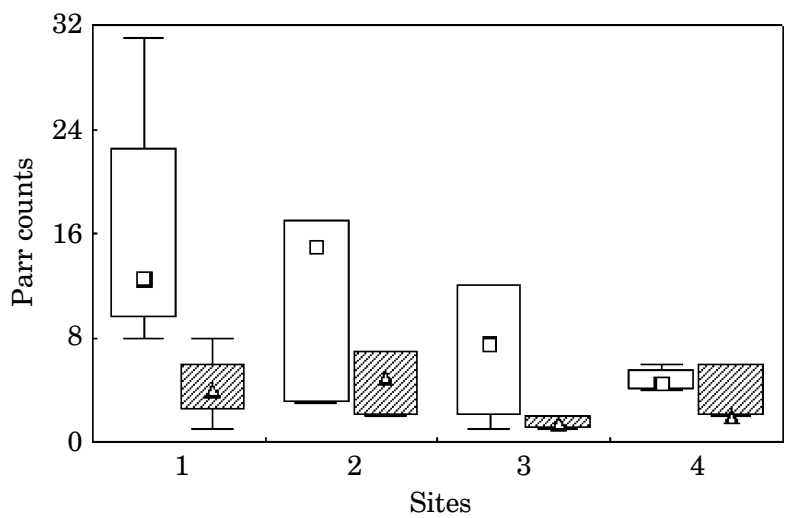

Fig. 4. Near-shore ( $\square$ ) and mid-stream (שת/ ) median (box: 25\%, 75\%; whisker: non-outlier minimum, non-outlier maximum) counts of Atlantic salmon parr sampled at four sites on four occasions in the Sainte-Marguerite River. The descriptive statistics are based on the near-shore and mid-stream counting strips, respectively, at each site over the four sampling occasions $(n=8$, with the exception of the mid-stream zone for site 2 where $n=4$ ). 
Luecke \& Wurtsbaugh (1993) found that hydroacustic estimates of pelagic density of Boneville ciscoes Prosopium gemmifer (Snyder) were 51\% lower during full moons than during new moons. More recently, Gaudreau \& Boisclair (2000) examined the influence of moon phase on population density estimates of dace Phoxinus eos (Cope) $\times$ Phoxinus neogaeus Cope and they noted that the population density estimates of dace were eight-fold lower, on average, during full-moons than during new-moons. These patterns were also thought to be due to predator avoidance. Based on the above studies, it is reasonable to predict that Atlantic salmon parr should exhibit stronger nocturnal predator avoidance (by hiding in the substratum) on nights with more ambient light. As a consequence, there should have been more visible Atlantic salmon parr above or on the substratum on new moon nights than on full moon nights. The results of this study, however, were not consistent with this prediction.

The nocturnal foraging efficiency of parr on bright nights $(c .35 \%$ of their daytime efficiency) is much better than their foraging efficiency during nights with overcast sky and no moon (Fraser \& Metcalfe, 1997). Due to their better ability to detect drift during bright nights, parr were expected to take advantage of the elevated nocturnal drift, resulting in more fish being active on full moon nights than on new moon nights. The present study did not support this prediction either.

In this study there were significantly more Atlantic salmon parr closer to shore than to the middle of the river at night. Similarly, the nocturnal density of visible juvenile rainbow trout was higher along the stream margins than in the middle of the channel (Riehle \& Griffith, 1993). In addition, several previous studies described juvenile Atlantic salmon (Metcalfe et al., 1997) and other salmonids being in slower water at night than during the day (Heggenes et al., 1993; Hill \& Grossman, 1993). While, in the absence of daytime data, the present results cannot be compared to daytime parr distributions in the sampled sites, they suggest that slower flowing and near shore areas of streams could contain a substantial part of the overall population at night; therefore, nighttime population assessments and habitat selection studies should include near shore areas in addition to areas closer to the middle of the stream.

In the present study the relative abundance of visible Atlantic salmon parr at night was not related to cloud cover. This is in contrast with Girard et al.'s (2003) study that indicated that the number of active parr during the day was negatively related to cloud cover. Girard et al. (2003) suggested that this finding was due, in part, to avian predator avoidance, because increasing cloud cover may improve the efficiency of common mergansers Mergus merganser L. to detect Atlantic salmon parr. It seems that, in the case of Atlantic salmon parr, diurnal predator pressure may be more important than nocturnal predation, as parr apparently avoid diurnally hunting fish-eating birds by hiding during the day or during periods with more cloud cover, but there is no difference in the number of visible fish between the new and full moon nights. From a methodological perspective, this study suggests that night-time sampling may be less affected by cloud cover than daytime sampling.

Previous studies showed that the activity of juvenile Atlantic salmon increased with increasing water temperature in the wild (Gries et al., 1997; Bremset, 2000; Breau, 2003) and in experimental channels (Fraser et al., 1993). 
The present study, however, found no relationship between the number of visible juvenile Atlantic salmon and night-time water temperature. Interestingly, another recent study (Girard et al., 2003) has shown a lack of significant relationship between the foraging activity of Atlantic salmon parr and water temperature. Quite conceivably, the absence of a statistically significant relationship between foraging behaviour or activity and water temperature noted in these two studies may be related to the fact that they were conducted over a relatively smaller range of water temperature (Girard et al., 2003: 16.5-21.7 $\mathrm{C}$; present study: $13-18^{\circ} \mathrm{C}$ ) than the studies noted earlier (Fraser et al., 1993: 2-18.5 C; Gries et al., 1997: 13-23 ${ }^{\circ}$; Bremset, 2000: $-0 \cdot 5-17 \cdot 3^{\circ} \mathrm{C}$; Breau, 2003: 13-27 ${ }^{\circ} \mathrm{C}$ ).

Although there was no information collected about parr movements and mortality, it is unlikely that substantial movement or mortality occurred during the study in the summer. Movement in or out of the monitored sites or losses due to mortality would have resulted in changes in the visible density of parr. As shown by the repeated measures ANOVA, however, the number of visible parr, on average, did not differ significantly between new moon and full moon or between first (30 June to 13 July 2003) and second (1 August to 14 August 2003) complete moon cycles.

The present study suggests that the nocturnal abundance of Atlantic salmon parr is not related to moon phase, cloud cover, river discharge (within a range of $3-5.7 \mathrm{~m}^{3} \mathrm{~s}^{-1} ; 1 \cdot 9$-fold change) and water temperature (within a range of $13-18^{\circ} \mathrm{C}$ ). The data collection, however, was performed in the summer and in only one river. It is not known if the results of this study may be generalized to other seasons and other rivers, or whether similar results would have been obtained using a different sampling method (e.g. electrofishing). Similarly, the conclusions of this study may apply only to visual surveys performed in the absence of rain. Nevertheless, these results suggest that a relatively flexible sampling strategy based on visual surveys may be developed to assess fish relative abundance on summer nights and that night sampling can be conducted without taking the above conditions into consideration.

This study would have not been possible without the dedicated work of M. Fradette, M. Picotin, S. Denizeau, M.-E. Bédard, F. Caty, G. Bourque, M. Dubé and H. Culhane-Palmer. Logistical support was provided by the CIRSA (Centre Interuniversitaire de Recherche sur le Saumon Atlantique) research station. This manuscript was greatly improved by the comments of G. Bremset and an anonymous reviewer. This research was supported by a Fonds de Recherche sur la Société et la Culture (FCAR) strategic grant to D. Boisclair, and by postdoctoral fellowships from FCAR and CIRSA to I. Imre.

\section{References}

Amundsen, P.-A., Bergersen, R., Huru, H. \& Heggberget, T. G. (1999). Diel feeding rhythms and daily food consumption of juvenile Atlantic salmon in the River Alta, northern Norway. Journal of Fish Biology 54, 58-71. doi: 1006/jfbi.1998.0844

Amundsen, P.-A., Gabler, H.-M., Herfindal, T. \& Riise, L. S. (2000). Feeding chronology of Atlantic salmon parr in subarctic rivers: consistency of nocturnal feeding. Journal of Fish Biology 56, 676-686. doi: 10.1006/jfbi.1999.1187

Armstrong, J. D., Grant, J. W. A., Forsgren, H. L., Fausch, K. D., DeGraaf, R. M., Fleming, I. A., Prowse, T. D. \& Schlosser, I. J. (1998). The application of science to 
the management of Atlantic salmon (Salmo salar): integration across scales. Canadian Journal of Fisheries and Aquatic Sciences 55 (Suppl. 1), 303-311.

Bachman, R. A. (1984). Foraging behaviour of free-ranging wild and hatchery brown trout in a stream. Transactions of the American Fisheries Society 113, 1-32.

Breau, C. (2003). Individual variability in activity patterns of juvenile Atlantic salmon (Salmo salar). Master's thesis, Concordia University, Quebec, Canada.

Bremset, G. (2000). Seasonal and diel changes in behaviour, microhabitat use and preferences by young pool-dwelling Atlantic salmon, Salmo salar, and brown trout, Salmo trutta. Environmental Biology of Fishes 59, 163-179.

Comeau, S. \& Boisclair, D. (1998). Day-to-day variation in fish horizontal migration and its potential consequence on estimates of trophic interactions in lakes. Fisheries Research 35, 75-81.

Contor, C. R. \& Griffith, J. S. (1995). Nocturnal emergence of juvenile rainbow trout from winter concealment relative to light intensity. Hydrobiologia 299, 179-183.

Elliott, J. M. (1970). Diel changes in invertebrate drift and the food of trout Salmo trutta L. Journal of Fish Biology 2, 161-165.

Elliott, J. M. (1973). The food of brown and rainbow trout (Salmo trutta and S. gairdneri) in relation to the abundance of drifting invertebrates in a mountain stream. Oecologia 12, 329-347.

Fraser, N. H. C. \& Metcalfe, N. B. (1997). The cost of being nocturnal: feeding efficiency in relation to light intensity in juvenile Atlantic salmon. Functional Ecology 11, 385-391.

Fraser, N. H. C., Metcalfe, N. B. \& Thorpe, J. E. (1993). Temperature dependent switch between diurnal and nocturnal foraging in salmon. Proceedings of the Royal Society of London B 252, 135-139.

Fraser, N. H. C., Heggenes, J., Metcalfe, N. B. \& Thorpe, J. E. (1995). Low summer temperatures cause juvenile Atlantic salmon to become nocturnal. Canadian Journal of Zoology 73, 446-451.

Gaudreau, N. \& Boisclair, D. (2000). Influence of moon phase on acoustic estimates of the abundance of fish performing daily horizontal migration in a small oligotrophic lake. Canadian Journal of Fisheries and Aquatic Sciences 57, 581-590.

Girard, I. (2002). Foraging and growth in relation to habitat use of young-of-the-year Atlantic salmon (Salmo salar). MSc thesis, Concordia University, Montréal, Canada.

Girard, P., Boisclair, D. \& Leclerc, M. (2003). The effect of cloud cover on the development of habitat quality indices for juveniles of Atlantic salmon (Salmo salar). Canadian Journal of Fisheries and Aquatic Sciences 60, 1386-1397.

Gordon, N. D., McMahon, T. A. \& Finlayson, B. L. (1992). Stream Hydrology: an Introduction for Ecologists. Chichester: John Wiley \& Sons Ltd.

Gries, G., Whalen, K. G., Juanes, F. \& Parrish, D. L. (1997). Nocturnal activity of juvenile Atlantic salmon (Salmo salar) in late summer: evidence of diel activity partitioning. Canadian Journal of Fisheries and Aquatic Sciences 54, 1408-1413.

Guay, J. C., Boisclair, D., Rioux, D., Leclerc, M., Lapointe, M. \& Legendre, P. (2000). Development and validation of numerical habitat models for juveniles of Atlantic salmon (Salmo salar). Canadian Journal of Fisheries and Aquatic Sciences 57, 2065-2075.

Guay, J. C., Boisclair, D., Leclerc, M. \& Lapointe, M. (2003). Assessment of the transferability of biological habitat models for juveniles of Atlantic salmon (Salmo salar). Canadian Journal of Fisheries and Aquatic Sciences 60, 1398-1408.

Heggenes, J., Krog, O. M. W., Lindås, O. R., Dokk, J. G. \& Bremnes, T. (1993). Homeostatic behavioural responses in a changing environment: brown trout (Salmo trutta) become nocturnal during winter. Journal of Animal Ecology 62, 295-308.

Hill, J. \& Grossman, G. D. (1993). An energetic model of microhabitat use for rainbow trout and rosyside dace. Ecology 74, 685-698.

Imre, I. \& Boisclair, D. (2004). Age effects on diel activity patterns of juvenile Atlantic salmon: parr are more nocturnal than young-of-the-year. Journal of Fish Biology 64, 1731-1736. doi: 10.1111/j.1095-8649.2004.00417.x 
Kalleberg, H. (1958). Observations in a stream tank of territoriality and competition in juvenile salmon and trout (Salmo salar L. and S. trutta L.). Report of the Institute of Freshwater Research, Drottningholm 39, 55-98.

Luecke, C. \& Wurtsbaugh, W. A. (1993). Effects of moonlight and daylight on hydroacoustic estimates of pelagic fish abundance. Transactions of the American Fisheries Research Society 122, 112-120.

Metcalfe, N. B., Valdimarsson, S. K. \& Fraser, N. H. C. (1997). Habitat profitability and choice in a sit-and-wait predator: juvenile salmon prefer slower currents on darker nights. Journal of Animal Ecology 66, 866-875.

Poff, N. L. \& Huryn, A. D. (1998). Multi-scale determinants of secondary production in Atlantic salmon (Salmo salar) streams. Canadian Journal of Fisheries and Aquatic Sciences 55 (Suppl. 1), 201-217.

Riehle, M. D. \& Griffith, J. S. (1993). Changes in habitat use and feeding chronology of juvenile rainbow trout (Oncorhynchus mykiss) in fall and the onset of winter in Silver Creek, Idaho. Canadian Journal of Fisheries and Aquatic Sciences 50, 2119-2128.

StatSoft (1995). Statistica for Windows, 2nd edn. Tulsa, OK: Statsoft, Inc.

Valdimarsson, S. K. \& Metcalfe, N. B. (1999). Effect of time of day, time of year, and life history strategy on time budgeting in juvenile Atlantic salmon, Salmo salar. Canadian Journal of Fisheries and Aquatic Sciences 56, 2397-2403.

Wańkowski, J. W. J. \& Thorpe, J. E. (1979). Spatial distribution and feeding in Atlantic salmon, Salmo salar L. juveniles. Journal of Fish Biology 14, 239-247.

Waters, T. F. (1962). Diurnal periodicity in the drift of stream invertebrates. Ecology 43, 316-320. 